\title{
Marsupial extension in terrestrial isopods (Crustacea, Isopoda, Oniscidea)
}

\author{
Carina Appel, Aline F. Quadros and Paula B. Araujo
}

(CA, PBA) Departamento de Zoologia, Universidade Federal do Rio Grande do Sul. Avenida Bento Gonçalves, 9500, prédio 43435, 91501-970, Porto Alegre, RS, Brazil. E-mails: (CA)carinaappel@yahoo.com.br, (PBA)pabearaujo@gmail.com

(AFQ) Universidade Federal da Integração Latino-Americana (UNILA), Parque Tecnológico Itaipu (PTI). Avenida Tancredo Neves, 6731, Caixa Postal: 2044. Foz do Iguaçu, PR, Brasil, CEP: 85856-970. E-mail: quadros.af@gmail.com

\section{Abstract}

In Oniscidea, the marsupium is a ventral pouch where the offspring develop independently of an external water source. The marsupium is formed by five pairs of overlapping oostegites that develop in the females during their reproductive period. In this study, ovigerous females of 35 species were dissected, their oostegites were extracted, and the intra-marsupial offspring were counted. Two marsupium forms were recognized: distended, in which the oostegites protrude distally in relation to the sternites; and non-distended, in which the oostegites are parallel to the sixth and seventh sternites. Armadillidium nasatum, A. vulgare, Pudeoniscus birabeni, Circoniscus gaigei and Cubaris murina, conglobating species with a non-distended marsupium, and Neotroponiscus daguerri and N. carolii, non-conglobating species with a distended marsupium, have a concavity on the ventral floor of the 6th and 7th pereionites, here called the marsupial extension. This is the first record of a marsupial extension which extends beyond the area formed by the oostegites in Oniscidea.

Key words: Conglobation, marsupium, oostegites, woodlice.

\section{Introduction}

Among the several adaptations that have allowed isopods to occupy terrestrial environments is the marsupium, an incubator pouch that allows the eggs to develop independently of an external source of water (Hoese, 1984). In Oniscidea, there are two types of marsupium (Hoese, 1984). The amphibious marsupium, found in Ligia spp., is open anteriorly and posteriorly. It has internal circulation of water by capillary action through the 6th and 7 th pereiopods. The terrestrial type is closed, and provides mechanical protection for the developing offspring (Hoese, 1984; Hoese and Janssen 1989). The marsupium is formed during the parturial molt (Suzuki and Yamasaki, 1989), when five pairs of oostegites appear and grow from the coxae of pereiopods 1-5, protruding toward the median longitudinal axis of the ventral body surface, and overlapping each other (Patane, 1940). Each oostegite consists 
of a thin translucent and impermeable cuticle (Patane, 1940; Hoese, 1984). Both the constitution and the way that the oostegites are organized and linked allow the expansion of the marsupial space to accommodate the offspring. In Crinocheta, the cotyledons are responsible for nutrition and oxygenation of the offspring inside the marsupium (Akahira, 1956; Hoese and Janssen, 1989). During comparative studies on morphological patterns of the cotyledons in several species of terrestrial isopods, a new marsupial configuration was observed, here called a marsupial extension. This study aimed to: (i) identify which species among those studied possess this marsupial extension, and (ii) to count the number of individuals housed inside this cavity.

\section{Materials and Methods}

Ovigerous females of 35 species from 11 families of terrestrial isopods, from the Collection of Crustaceans of the Zoology Department - UFRGS and from donations and collections, were analyzed. The females were fixed in Dubosc fixative (Humason, 1972), and were dissected and photographed before and after the removal of the oostegites and of the offspring contained in the marsupium. The offspring were counted and classified according to their stage of development, following Milatovič et al. (2010): egg with undifferentiated embryo (S1 to S8), differentiated embryo (S9 to S18, when the appendix, eyes and segmentation are visible in the vitelline membrane), and manca (S19, when the isopod is already free of the membrane).

\section{Results and Discussion}

Among the 35 terrestrial isopod species examined, seven species possessed the marsupial extension (Table I). The marsupial extension is a concavity on the sternites of the 6th and 7 th pereionites. This concavity starts from the fifth sternite, where the last pair of oostegites closes the marsupium (Figs. 1C,
1D). Inside this cavity there is a portion of the developing offspring, which are in the same developmental stage as the rest of the offspring in the marsupium. The proportion of the offspring in the extension is very significant, usually more than $10 \%$ and up to $25 \%$ of the total fecundity (Table II). For example, one female Armadillidium nasatum Budde-Lund, 1885 had 116 eggs in the marsupium and 23 eggs in the marsupial extension (Table II). The number of offspring inside the extension seems to be proportional to the total fecundity, which is in turn related to the female size (Quadros et al., 2009).

Among the species that have the marsupial extension, a different marsupial form was also noted. The most common marsupial form in Oniscidea is a distended type, i.e., in which the oostegites protrude distally in relation to the sternites (Figs. 1A, 2A). Among the species examined, 30 have the distended marsupium (Table 1). On the other hand, the conglobating species $A$. nasatum, $A$. vulgare (Latreille, 1804), Circoniscus gaigei Pearse, 1979, Cubaris murina Brandt, 1833 and Pudeoniscus birabeni Vandel, 1963 have a nondistended marsupium, where the oostegites are parallel to the sixth and seventh sternites (Figs. 1B; 2B; Table 1). A comparison of the internal space of the marsupia revealed that in the distended marsupium, the oostegites bend outwards when the growing embryos require more volume (Fig. 1A). However, in those species with a marsupial extension, the oostegites bend only slightly, and the sternites arch into the body cavity to provide more space for the embryos (Fig. 1B). This leads to a displacement of the female's internal organs (Fig. 1B). Possibly, this displacement results in compression of the organs, which in advanced stages may cause females to cease feeding. In fact, all females with a marsupial extension and non-distended marsupium examined showed a full gut only when they were carrying eggs with undifferentiated embryos (Fig. 2E). Females carrying embryos and mancas, when dissected, showed an empty gut, with no trace of food (Fig. 2F). Females with a distended marsupium, regardless of the intra-marsupial 
Table I. Configuration of the marsupium in terrestrial isopods and the presence of a marsupial extension and the conglobating ability. $\mathrm{N}=$ number of ovigerous females examined.

\begin{tabular}{|c|c|c|c|c|c|}
\hline \multirow[b]{2}{*}{ Family/species } & \multicolumn{4}{|c|}{ Marsupium } & \multirow{2}{*}{ Conglobation } \\
\hline & $\mathrm{N}$ & Distended & $\begin{array}{c}\text { Non- } \\
\text { distended }\end{array}$ & $\begin{array}{c}\text { With } \\
\text { extension }\end{array}$ & \\
\hline \multicolumn{6}{|l|}{$\begin{array}{l}\text { Armadillidae } \\
\text { Cubaris murina Brandt, } 1833\end{array}$} \\
\hline \multicolumn{6}{|l|}{ Armadillidiidae } \\
\hline Armadillidium vulgare (Latreille, 1804) & 20 & & X & X & $\mathrm{X}$ \\
\hline Armadillidium nasatum Budde-Lund, 1885 & 49 & & $\mathrm{X}$ & $\mathrm{X}$ & $\begin{array}{l}\Lambda \\
X\end{array}$ \\
\hline \multicolumn{6}{|l|}{ Balloniscidae } \\
\hline Balloniscus glaber Araujo \& Zardo, 1996 & 5 & $X$ & & & \\
\hline Balloniscus sellowii (Brandt, 1833) & 53 & $\begin{array}{l}\lambda \\
X\end{array}$ & & & \\
\hline \multicolumn{6}{|l|}{ Bathytropidae } \\
\hline Neotroponiscus carolii Arcangeli, 1936 & 1 & $X$ & & $\mathrm{X}$ & \\
\hline Neotroponiscus daguerrii (Giambiagi de Calabrese, 1939) & 5 & $\begin{array}{l}\lambda \\
X\end{array}$ & & $\mathrm{X}$ & \\
\hline \multicolumn{6}{|l|}{ Dubioniscidae } \\
\hline Novamundoniscus meridionalis (Araujo \& Buckup, 1994) & 3 & $X$ & & & \\
\hline Novamundoniscus gracilis Lopes \& Araujo, 2003 & 1 & $\mathrm{X}$ & & & \\
\hline \multicolumn{6}{|l|}{ Philoscidae } \\
\hline Atlantoscia floridana (van Name, 1940) & 17 & $X$ & & & \\
\hline Atlantoscia rubromarginata Araujo \& Leistikow, 1999 & 1 & $\begin{array}{l}X \\
X\end{array}$ & & & \\
\hline Benthana araucariana Araujo \& Lopes, 2003 & 2 & $\begin{array}{l}\lambda \\
X\end{array}$ & & & \\
\hline Benthana cairensis Sokolowicz, Boelter \& Araujo, 2008 & 20 & $\mathrm{X}$ & & & \\
\hline Benthana convexa Lemos de Castro, 1958 & 4 & $\begin{array}{l}\Lambda \\
X\end{array}$ & & & \\
\hline Benthana longicornis Verhoeff, 1941 & 4 & $\begin{array}{l}\Lambda \\
X\end{array}$ & & & \\
\hline Benthana longipenis Lemos de Castro, 1958 & 4 & $\begin{array}{l}\lambda \\
X\end{array}$ & & & \\
\hline Benthana picta (Brandt, 1833) & 1 & $\mathrm{X}$ & & & \\
\hline Benthana taeniata Araujo \& Buckup, 1994 & 6 & $\begin{array}{l}\Lambda \\
X\end{array}$ & & & \\
\hline Benthana itaipuensis Campos-Filho \& Araujo, 2011 & 2 & $\begin{array}{l}\lambda \\
X\end{array}$ & & & \\
\hline Burmoniscus meeusei (Holthuis, 1947) & 4 & $\mathrm{X}$ & & & \\
\hline Littorophiloscia denticulata (Ferrara \& Taiti, 1982) & 1 & $\begin{array}{l}\lambda \\
X\end{array}$ & & & \\
\hline \multicolumn{6}{|l|}{ Platyarthridae } \\
\hline Trichorhina acuta Araujo \& Buckup, 1994 & 5 & $X$ & & & \\
\hline Trichorhina argentina Vandel, 1963 & 3 & $\mathrm{X}$ & & & \\
\hline Trichorhina heterophthalma Lemos de Castro, 1964 & 3 & $\begin{array}{l}\Lambda \\
X\end{array}$ & & & \\
\hline Trichorhina tomentosa (Budde-Lund, 1893) & 2 & X & & & \\
\hline \multicolumn{6}{|l|}{ Porcellionidae } \\
\hline Agabiformius lentus (Budde-Lund, 1885) & 5 & $\mathrm{X}$ & & & \\
\hline Porcellio dilatatus Brandt, 1833 & 11 & $\mathrm{X}$ & & & \\
\hline Porcellio laevis Latreille, 1804 & 4 & $\begin{array}{l}\Lambda \\
X\end{array}$ & & & \\
\hline Porcellio scaber Latreille, 1804 & 15 & X & & & \\
\hline Porcellionides pruinosus (Brandt, 1833) & 10 & $\begin{array}{l}\lambda \\
X\end{array}$ & & & \\
\hline Porcellionides sexfasciatus (Budde-Lund, 1885) & 8 & $\begin{array}{l}\hat{X} \\
\mathrm{X}\end{array}$ & & & \\
\hline \multicolumn{6}{|l|}{ Pudeoniscidae } \\
\hline Pudeoniscus birabeni Vandel, 1963 & 2 & & $\mathrm{X}$ & $\mathrm{X}$ & $X$ \\
\hline \multicolumn{6}{|l|}{ Scleropactidae } \\
\hline Circoniscus gaigei Pearse, 1917 & 2 & & X & $X$ & X \\
\hline \multicolumn{6}{|l|}{ Trachelipodidae } \\
\hline Nagurus cristatus (Dollfus, 1889) & 4 & $X$ & & & \\
\hline Nagurus nanus (Budde-Lund, 1908) & 5 & $X$ & & & \\
\hline
\end{tabular}


Table II. The distribution of the offspring in terrestrial isopods that have a marsupial extension. Fecundity is given as the total number of offspring per female and the number of offspring inside the marsupial extension (within parenthesis). The letters indicate the developmental stage: eg = egg with undifferentiated embryo; em = differentiated embryo; $\mathrm{m}=$ manca (see Material \& Methods for details).

\begin{tabular}{|c|c|}
\hline Species & Fecundity \\
\hline A. nasatum & $\begin{array}{l}\text { 57(15)em; 98(22)eg; 96(12)eg; 53(6)m; 58(11)em; 69(12) m; 56(8)em; 91(15) } \\
\text { em; 80(13)em; 70(9)em; 65(7)em; 83(10)em; 87(15)em; 67(6)eg; 83(10)m; } \\
\text { 88(7)eg; 75(12)m; 81(10)eg; 99(15)em; 73(13) m; 77(9)eg; 67(8)em; 101(8) } \\
\text { em; 45(8)m; 58(7)eg; 48(8)em; 85(8)eg; 72(9)em; 65(8)eg; 66(6)eg; 139(23) } \\
\text { eg; 72(9)eg; 65(8)eg; 69(9)eg; 83(10)m; 76(11)em; 79(15)m; 77(9)eg; 58(8)em; } \\
\text { 58(10)m; 62(9)m; 61(7)eg; 94(12)m; 61(5)em; 56(6)m; 65(7)em; 72(12)eg; } \\
\text { 66(9)em; 79(11)em; }\end{array}$ \\
\hline A. vulgare & $\begin{array}{l}\text { 70(15)m; 74(14)eg; 137(20)m; 61(11)m; 85(12)eg; 96(18)eg; 102(15)m; } \\
\text { 78(11)eg; 54(6)m; 52(5)em; 60(5)m; 51(5)em; 69(6)m; 53(5)eg; 67(12)m; } \\
\text { 121(26)m; 57(8)m; 93(16)em; 51(9)m; 31(5)em; }\end{array}$ \\
\hline C. gaigei & 18(5)eg; 18(6) eg; \\
\hline C. murina & $12(3) \mathrm{m} ; 14(4) \mathrm{m}$ \\
\hline N. carolii & 8(2)em; \\
\hline N. daguerri & 14(3)eg; 12(3)eg; 12(2)em; 4(2) m; 5(2)m; \\
\hline P. birabeni & 7(3)eg; 7(2)eg; \\
\hline
\end{tabular}

A

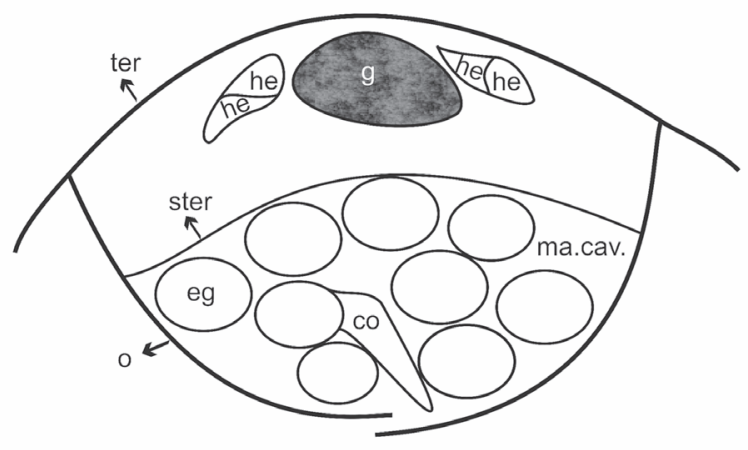

B

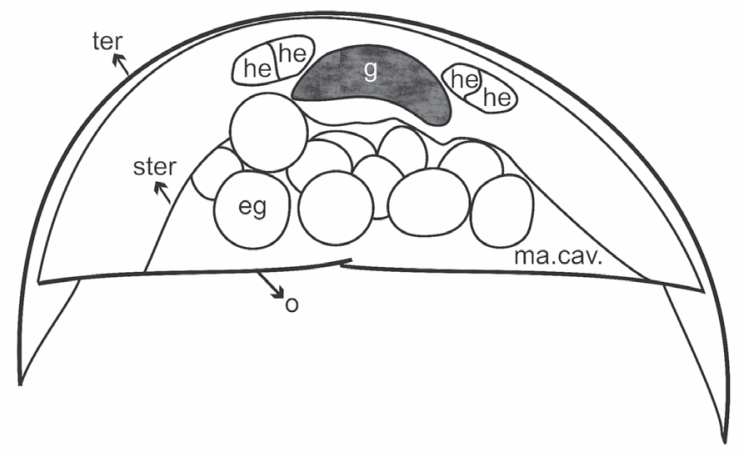

Figure 1. Schematic cross-section of the pereion of terrestrial isopods showing two marsupial forms. A, distended (drawn from Balloniscus sellowii). B, non-distended, Armadillidium vulgare. co: cotyledon; eg: egg; he: hepatopancreas; hg: hindgut; ma cav: marsupial cavity; o: oostegites; ster: sternite; ter: tergite. Bar: $0.5 \mathrm{~mm}$.

development stage, always showed a full gut (Fig. 2G).

Another important point is that in species belonging to the ecomorphological category of the "rollers" (Schmalfuss, 1984), the lack of a large distention of the marsupium allows ovigerous females to conglobate. However, it is noteworthy that among the species that have a marsupial extension, two, Neotroponiscus carolii Arcangeli, 1936 and $N$. daguerrii
(Giambiagi de Calabrese, 1939), are nonconglobating species. Information on the presence or absence of the marsupial extension in species in families and genera that were not considered in this study is necessary to understand the evolution of the conglobating ability, which is considered a convergence that evolved within the Tylidae, once in Synocheta, and several times within the Crinocheta (Schmidt, 2002). The marsupial form must 

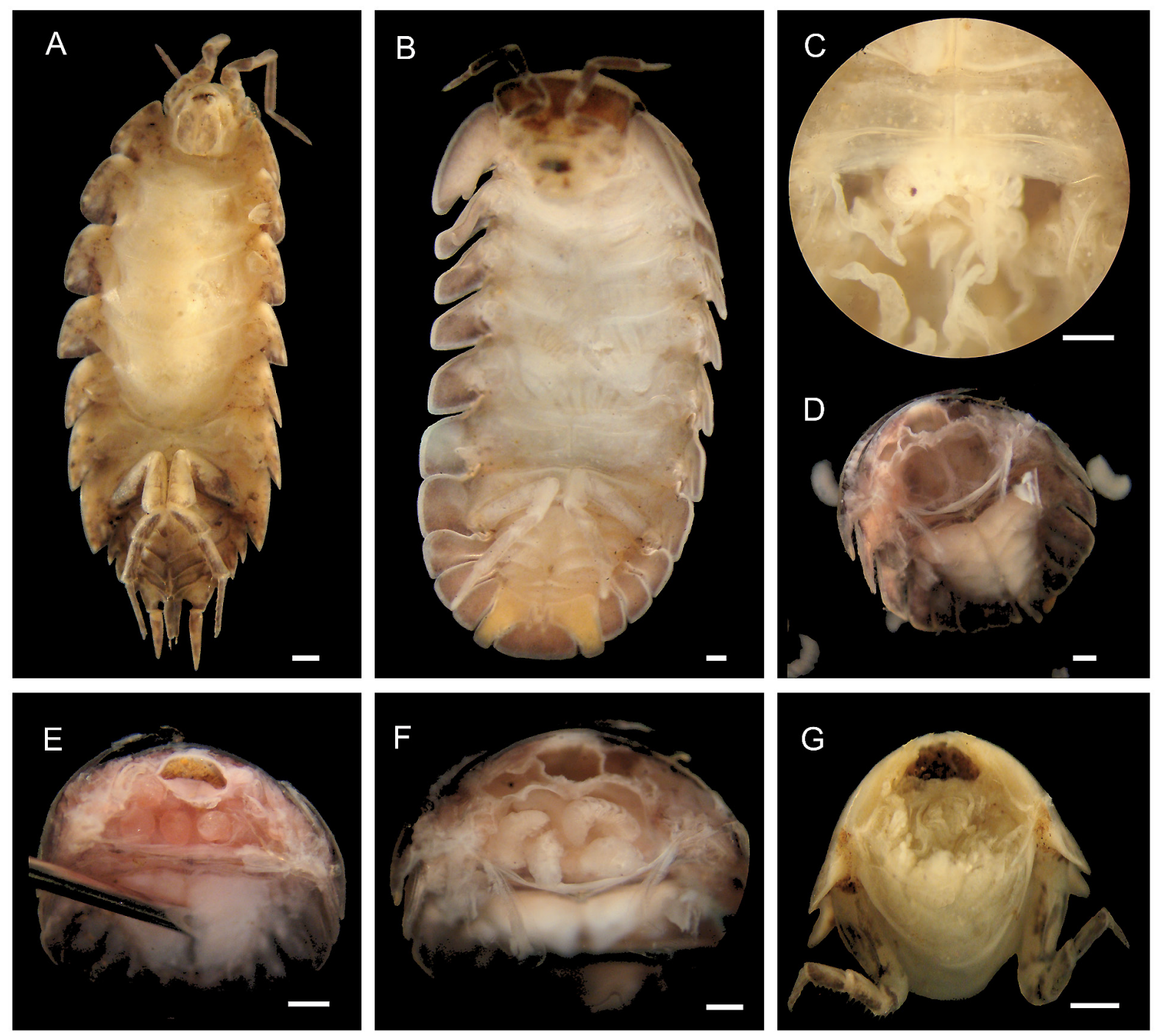

Figure 2. Marsupium in terrestrial isopods. A, distended marsupium in Balloniscus sellowii. B, non-distended marsupium in the conglobating Cubaris murina. C, manca of $C$. murina inside the marsupial extension. D, empty marsupial extension of Armadillidium vulgare, showing the space occupied by mancas upon their removal. E, beginning of the ovigerous period in $A$. vulgare, showing eggs and food inside the gut. F, late ovigerous period in $A$. vulgare, showing the mancas and an empty gut. G, late ovigerous period in $B$. sellowii, showing the mancas and the food inside the gut. Bar: $0.5 \mathrm{~mm}$.

also be considered in future studies on the phylogeny within Oniscidea. To date, no similar structure has been found in Peracarida and for a better understanding of the structure of this extension structure and its implications for the life history of these species, further studies are needed.

\section{Acknowledgements}

We are grateful to Daniel Rodrigues, Jonathas T. Lisboa, Júlia C. Niemeyer, Bianca L. Zimmermann and Ivanklin S. CamposFilho for donating specimens of several species used in the present study, to CAPES (Coordenação de Aperfeiçoamento de Pessoal de Nível Superior) for a scholarship to CA and to CNPq (Conselho Nacional de Desenvolvimento Científico e Tecnológico) for a production scholarship to PBA

\section{References}

Akahira, Y. 1956. The function of thoracic processes found in females of the common woodlouse, Porcellio scaber. Journal Faculty of Science, Hokkaido University, 12:493498. 
Hoese, B. 1984. The marsupium in terrestrial isopods. Symposium of the Zoological Society of London, 53:65-76.

Hoese, B. and Janssen, H.H. 1989. Morphological and physiological studies on the marsupium in terrestrial isopods. Monitore Zoologico Italiano (N.S.) Monography, 4:153-173.

Humason, G.L. 1972. Animal Tissue Techniques. San Francisco, W.H. Freeman and Company, 641p.

Milatovič, M.; Kostanjšek, R. and Štrus, J. 2010. Ontogenetic development of Porcellio scaber: staging based on microscopic anatomy. Journal of Crustacean Biology, 30(2):225-235.

Patane, L. 1940. Sulla struttura e la funzione del marsupio di Porcellio laevis Latreille. Archivio Zoologico Italiano, 28:271-296.

Quadros, A.; Araujo, P.B. and Sokolowicz, C.C. 2008. Reproduction of neotropical isopods (Crustacea: Oniscidea) in southern Brazil: similarities and differences relative to temperate and tropical species. p. 81-90. In: M. Zimmer, F. Charfi-Cheikhrouha and S. Taiti (eds), Proceedings of the International Symposium of Terrestrial Isopod Biology. Shaker Verlag, Aachen.

Suzuki, S. and K. Yamasaki. 1989. Ovarian control of oostegite formation in Armadillidium vulgare (Crustacea, Isopoda). Zoological Science, 6:11-32.

Schmalfuss, H. 1984. Eco-morphological strategies in terrestrial isopods. Symposium of the Zoological Society of London, 53:4963.

Schmidt, C. 2002. Contribution to the phylogenetic system of the Crinocheta (Crustacea, Isopoda). Part 1 (Olibrinidae to Scyphaidae s. str). Mitteilungen aus dem Museum für Naturkunde in Berlin, Zoologische Reihe, 78: 275-352.

Submitted 31 March 2011

Accepted 30 September 2011 